\title{
Pulmonary hypertension in COPD: results from the ASPIRE registry
}

\author{
Judith Hurdman*, Robin Condliffe*,\#, Charlie A. Elliot*,\#, Andrew Swift ${ }^{*, \text {, }}$ \\ Smitha Rajaram ${ }^{\star}$, Christine Davies ${ }^{+}$, Catherine Hill ${ }^{+}$, Neil Hamilton*, \\ lain J. Armstrong*, Catherine Billings ${ }^{\S}$, Lauren Pollard ${ }^{\S}$, Jim M. Wild ${ }^{\#,}$, \\ Allan Lawrie ${ }^{f}$, Rod Lawson**, lan Sabroe ${ }^{\star, \#, \# \#}$ and David G. Kiely*,\#
}

ABSTRACT: The phenotype and outcome of severe pulmonary hypertension in chronic obstructive pulmonary disease (COPD) is described in small numbers, and predictors of survival are unknown. Data was retrieved for 101 consecutive, treatment-naïve cases of pulmonary hypertension in COPD.

Mean \pm SD follow-up was $2.3 \pm 1.9$ years. 59 patients with COPD and severe pulmonary hypertension, defined by catheter mean pulmonary artery pressure $\geqslant \mathbf{4 0} \mathbf{~ m m H g}$, had significantly lower carbon monoxide diffusion, less severe airflow obstruction but not significantly different emphysema scores on computed tomography compared to 42 patients with mild-moderate pulmonary hypertension. 1- and 3-year survival for severe pulmonary hypertension, at $70 \%$ and $33 \%$, respectively, was inferior to $83 \%$ and $55 \%$, respectively, for mild-moderate pulmonary hypertension. Mixed venous oxygen saturation, carbon monoxide diffusion, World Health Organization functional class and age, but not severity of airflow obstruction, were independent predictors of outcome. Compassionate treatment with targeted therapies in 43 patients with severe pulmonary hypertension was not associated with a survival benefit, although improvement in functional class and/or fall in pulmonary vascular resistance $>\mathbf{2 0} \%$ following treatment identified patients with improved survival.

Standard prognostic markers in COPD have limited value in patients with pulmonary hypertension. This study identifies variables that predict outcome in this phenotype. Despite poor prognosis, our data suggest that further evaluation of targeted therapies is warranted.

KEYWORDS: Chronic obstructive pulmonary disease, computed tomography, emphysema, prognosis, pulmonary hypertension, respiratory function tests

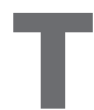
he development of pulmonary hypertension $(\mathrm{PH})$ in chronic lung diseases such as chronic obstructive pulmonary disease (COPD) has both functional and prognostic implications $[1,2]$. PH in COPD (PH-COPD) is usually mild to moderate with preserved cardiac output, and evolves slowly alongside the progression of lung disease and hypoxaemia [3]. However, a minority of patients develop severe $\mathrm{PH}$ with elevations in pulmonary artery pressure that have been described as "out of proportion" to the underlying COPD [4, 5]. Hypotheses for the aetiology of this phenotype include greater susceptibility to alveolar hypoxia and/or tobacco smoke [6, 7], destruction of the capillary vascular bed [8], inflammatory factors initiating remodelling of the pulmonary vascular bed [9-11] or the coexistence of idiopathic pulmonary arterial hypertension (IPAH) in patients with lung disease [4].

Severe PH-COPD has been arbitrarily defined by a resting mean pulmonary artery pressure (PAP) $\geqslant 40 \mathrm{mmHg}$ and occurs in $\sim 1 \%$ of patients with chronic respiratory failure related to COPD [4]. The high and increasing prevalence of COPD [12-14] and the substantial consequences of developing severe $\mathrm{PH}$ have generated increasing interest in PH-COPD; however in this group the employment of targeted pulmonary vascular therapy, while attractive, remains unproven [15].

The Sheffield Pulmonary Vascular Disease Unit delivers a supra-regional, adult UK PH service to
AFFLLIATIONS

*Sheffield Pulmonary Vascular Disease Unit, Royal Hallamshire Hospital, Sheffield,

\#NIHR Cardiovascular Biomedical Research Unit, Sheffield,

"Academic Unit of Radiology, University of Sheffield, Sheffield, ${ }^{+}$Dept of Radiology, Royal Hallamshire Hospital, Sheffield,

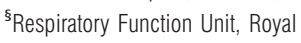
Hallamshire Hospital, Sheffield, ${ }^{f}$ Dept of Cardiovascular Science, University of Sheffield, Sheffield, **Dept of Respiratory Medicine, Royal Hallamshire Hospital,

Sheffield, and

\#\#Dept of Infection and Immunity, University of Sheffield, Sheffield, UK.

CORRESPONDENCE

D.G. Kiely

Sheffield Pulmonary Vascular

Disease Unit

Royal Hallamshire Hospital

Glossop Road

Sheffield

S10 2JF

UK

E-mail: david.kiely@sth.nhs.uk

Received:

May 182012

Accepted after revision:

Aug 232012

First published online:

Sept 272012 
a population with a COPD prevalence that is one of the highest in Europe [16]. The aim of this study was to compare the characteristics and outcomes of extensively phenotyped, consecutive patients with PH-COPD diagnosed at our specialist referral centre over a 9-year period.

\section{METHODS}

In the ASPIRE (Assessing the Spectrum of Pulmonary Hypertension Identified at a Referral Centre) registry, 1737 consecutive, incident, treatment-naïve patients with suspected PH underwent diagnostic evaluation between February 2001 and February 2010 as previously detailed [17]. Diagnostic classification was by standard criteria following systematic, multidisciplinary assessment that included echocardiography, detailed blood testing, pulmonary function testing, overnight oximetry, isotope perfusion scanning, high-resolution computed tomography (HRCT), CT pulmonary angiography, right heart catheter (RHC) and, from 2004, cardiopulmonary magnetic resonance imaging (fig. 1). Following this detailed assessment, 101 patients were assigned the diagnosis PH-COPD (updated clinical classification of pulmonary classification (Dana Point, CA, USA; 2008) class 3.1) [18] and comprise the cohort examined in this study. All patients underwent RHC in a supine position and $\mathrm{PH}$ was defined as mean PAP $\geqslant 25 \mathrm{mmHg}$ at rest [18], with mild-moderate PHCOPD defined as mean PAP $\geqslant 25 \mathrm{mmHg}$ and $<40 \mathrm{mmHg}$, and severe $\mathrm{PH}-\mathrm{COPD}$ defined by mean PAP $\geqslant 40 \mathrm{mmHg}$ [4].

For the purposes of this study PH-COPD refers to patients with COPD as defined by post-bronchodilator forced expiratory volume in $1 \mathrm{~s}$ (FEV1)/forced vital capacity ratio $\leqslant 0.7$ where airflow obstruction was due to a combination of airway and parenchymal damage, as per National Institute for Health and Clinical Excellence (NICE) guidelines updated in 2010 [19] or significant emphysema. The degree of emphysema and any coexisting pulmonary fibrosis were assessed using HRCT scan independently evaluated by two chest radiologists blinded to clinical data and each other's findings. A visual scale based on previous studies $[4,20,21]$ was used to score the degree of parenchymal abnormality in the upper, mid and lower zone of each lung $(0=<5 \%, 1=5-25 \%, 2=26-50 \%, 3=51-75 \%$ and $4=76-100 \%$ ) for both emphysema and fibrosis. In order to assess the distribution of parenchymal disease on HRCT for the purpose of this study, the sum of the right and left upper zone scores was compared to the sum of the right and left lower zone scores for emphysema and fibrosis, respectively. For computed tomography $(\mathrm{CT})$ scan acquisition parameters please see the online supplementary material.

Date of diagnosis was taken as date of first RHC demonstrating $\mathrm{PH}$. World Health Organization (WHO) functional class and pulmonary function tests (PFTs) [22, 23] obtained closest to the date of RHC were recorded as baseline measures. Exercise capacity was assessed using distance achieved during the incremental shuttle walking test (ISWD) [24].

The management of COPD was in accordance with contemporaneous guidelines $[12,19,25,26]$. Pulmonary vascular therapy was used on a compassionate basis in severe PH-COPD with prior agreement from funding bodies, as per UK national commissioning policy [27, 28]. Endothelin receptor antagonists (ERA), phosphodiesterase-5-inhibitors (PDE-5I), and prostanoids were used as monotherapy or in combination, as clinically indicated.

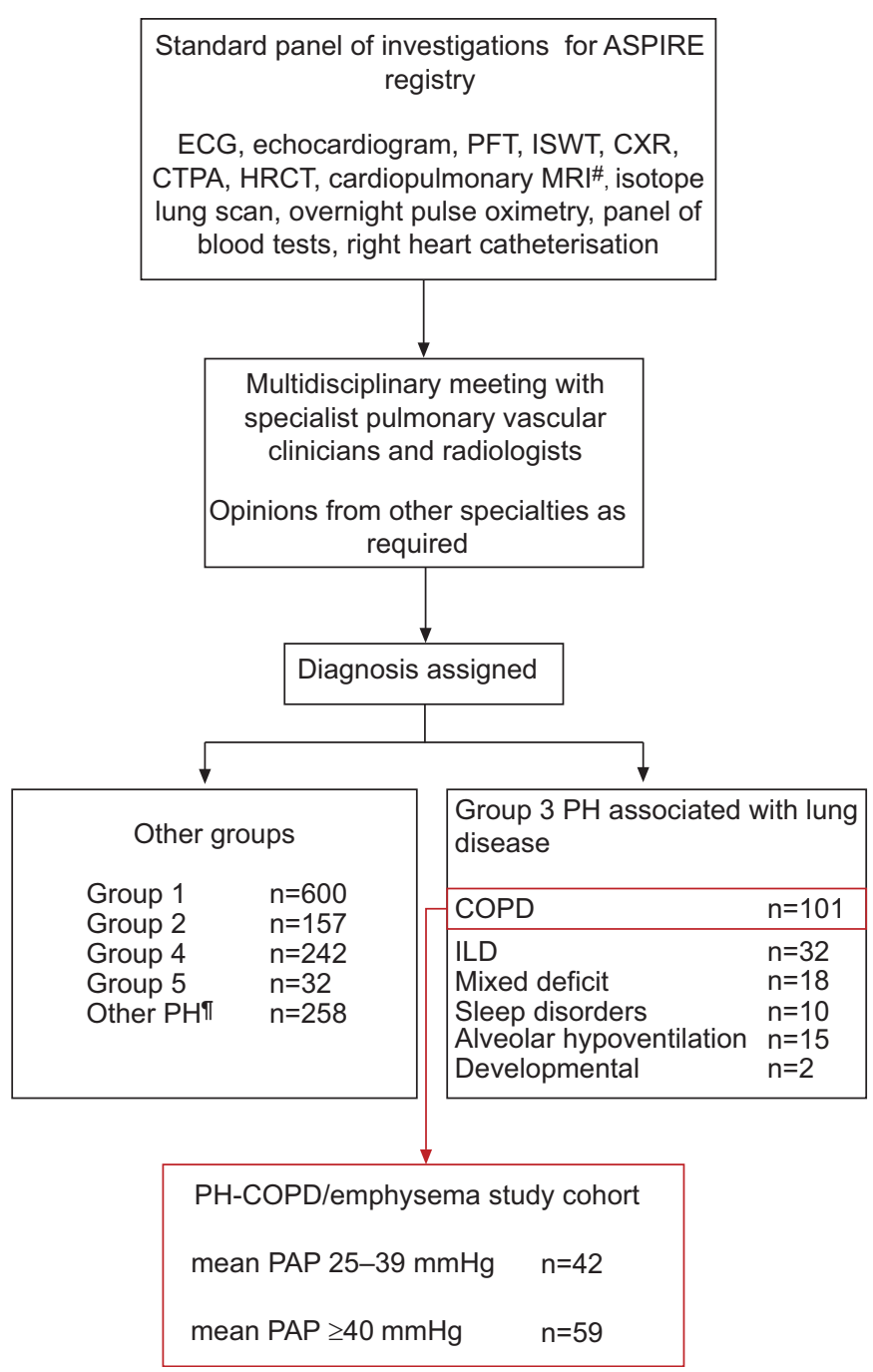

FIGURE 1. Diagnostic pathway. ASPIRE: Assessing the Spectrum of Pulmonary Hypertension Identified at a Referral Centre; PFT: pulmonary function testing; ISWT: incremental shuttle walking test; CXR: chest radiograph; CTPA: computed tomography pulmonary angiogram; HRCT: high-resolution computed tomography of the thorax; $\mathrm{MRI}$ : magnetic resonance imaging; $\mathrm{PH}$ : pulmonary hypertension; COPD: chronic obstructive pulmonary disease; ILD: interstitial lung disease; PAP: pulmonary artery pressure. \#: cardiopulmonary MRI was used routinely from 2004 onwards. ": Other $\mathrm{PH}$ included: $\mathrm{PH}$ multiple diagnoses $\mathrm{n}=38$, $\mathrm{PH}$ inclusion criteria not met $n=85, \mathrm{PH}$ lung with connective tissue disease $n=102$ and $\mathrm{PH}$ owing to heart disease and connective tissue disease $\mathrm{n}=33$.

The census point was date of death or August 1, 2011 in survivors. Mortality status was ascertained via the UK National Health Service enhanced reporting service death report. No patients were lost to follow-up. Ethical approval for analysis of routinely collected clinical data was granted by the North Sheffield Research Ethics Committee.

\section{Statistical analysis}

Continuous variables were described by mean \pm SD or, where nonparametric, median (interquartile range $(\mathrm{IQR})$ ). Comparisons between groups were performed using independent $t$-tests for parametric data and Mann-Whitney U-tests for nonparametric 
TABLE 1 Baseline characteristics

COPD mean PAP 25-39 mmHg

COPD mean PAP $\geqslant 40 \mathrm{mmHg}$

p-value

\begin{tabular}{|c|c|c|c|}
\hline Subjects $n$ & 42 & 59 & \\
\hline Age years & $67 \pm 11$ & $70 \pm 9$ & 0.092 \\
\hline Female & $\overline{45}$ & $3 \overline{1}$ & 0.130 \\
\hline BMI $\mathbf{k g} \cdot \mathrm{m}^{-2}$ & $28 \pm 8$ & $27 \pm 6$ & 0.520 \\
\hline \multicolumn{4}{|l|}{ Smoking } \\
\hline Never-smoker & 2 & 5 & $>0.05$ \\
\hline Ex-smoker & 78 & 83 & $>0.05$ \\
\hline Current smoker & 20 & 12 & $>0.05$ \\
\hline Tobacco pack-years & $45 \pm 28$ & $38 \pm 28$ & 0.295 \\
\hline Symptom duration months & $24(12-60)$ & $24(12-42)$ & $0.788^{\#}$ \\
\hline \multicolumn{4}{|l|}{ Comorbidities } \\
\hline Diabetes mellitus & 21 & 29 & 0.403 \\
\hline Systemic hypertension & 24 & 31 & 0.459 \\
\hline Atrial fibrillation & 17 & 22 & 0.505 \\
\hline Atrial flutter & 5 & 3 & 0.727 \\
\hline Left ventricular hypertrophy & 7 & 8 & 0.807 \\
\hline Ischaemic heart disease & 26 & 39 & 0.180 \\
\hline Valvular left heart disease & 12 & 7 & 0.373 \\
\hline Peripheral vascular disease & 5 & 14 & 0.145 \\
\hline Chronic kidney disease & 10 & 14 & 0.537 \\
\hline \multicolumn{4}{|l|}{ Exercise limitation } \\
\hline WHO-FC & & & 0.016 \\
\hline III & 74 & 61 & \\
\hline IV & 12 & 36 & \\
\hline ISWD m & $140(45-195)$ & $40(18-100)$ & $0.001^{\#}$ \\
\hline $\mathrm{SpO}_{2}$ on air \% & $87.8 \pm 6.9$ & $80.5 \pm 9.3$ & $<0.001$ \\
\hline Decrease in $\mathrm{SpO}_{2}$ during ISWT \% & $-11.2 \pm 8.5$ & $-7.9 \pm 6.2$ & 0.044 \\
\hline \multicolumn{4}{|l|}{ Arterial blood gases } \\
\hline \multicolumn{4}{|l|}{ On air } \\
\hline $\mathrm{PaCO}_{2} \mathrm{mmHg}$ & $45.0 \pm 9.8$ & $36.0 \pm 11.3$ & 0.010 \\
\hline $\mathrm{PaO}_{2} \mathrm{mmHg}$ & $56.3 \pm 9.8$ & $45.8 \pm 11.3$ & 0.004 \\
\hline Entrained oxygen flow $L \cdot \mathrm{min}^{-1}$ & $2.7 \pm 1.8$ & $5.3 \pm 3.9$ & 0.017 \\
\hline $\mathrm{PaCO}_{2} \mathrm{mmHg}$ & $46.5 \pm 16.5$ & $34.5 \pm 8.3$ & 0.005 \\
\hline $\mathrm{PaO}_{2} \mathrm{mmHg}$ & $72 \pm 18$ & $66.8 \pm 14.3$ & 0.331 \\
\hline \multicolumn{4}{|l|}{ Right heart catheter } \\
\hline Resting $\mathrm{SpO}_{2} \%$ & $93 \pm 4$ & $94 \pm 4$ & 0.342 \\
\hline Entrained $\mathrm{O}_{2} \mathrm{~L} \cdot \mathrm{min}^{-1}$ & $0(0-4)$ & $2.0(0-5.5)$ & $0.022^{\#}$ \\
\hline Mean RAP $\mathrm{mmHg}$ & $8 \pm 4$ & $12 \pm 5$ & 0.001 \\
\hline Mean PAP $\mathrm{mmHg}$ & $32 \pm 5$ & $49 \pm 8$ & $<0.001$ \\
\hline $\mathrm{CI} \mathrm{L} \cdot \min \cdot \mathrm{m}^{-2}$ & $3.2 \pm 0.8$ & $2.5 \pm 0.7$ & $<0.001$ \\
\hline PCWP mmHg & $13 \pm 5$ & $12 \pm 5$ & 0.156 \\
\hline PVR dyn $\cdot \mathbf{s} \cdot \mathrm{cm}^{-5}$ & $303 \pm 168$ & $755 \pm 377$ & $<0.001$ \\
\hline $\mathrm{SvO}_{2} \%$ & $67 \pm 8$ & $63 \pm 8$ & 0.051 \\
\hline \multicolumn{4}{|l|}{ Pulmonary function tests } \\
\hline FEV $1 \%$ pred & $51 \pm 28$ & $65 \pm 23$ & 0.006 \\
\hline FVC \% pred & $78 \pm 25$ & $90 \pm 24$ & 0.022 \\
\hline $\mathrm{FEV}_{1 / \mathrm{FVC}}$ & $0.51 \pm 0.18$ & $0.59 \pm 0.18$ & 0.041 \\
\hline DLCO \% pred & $40 \pm 20$ & $27 \pm 13$ & 0.001 \\
\hline \multicolumn{4}{|l|}{ CT scan } \\
\hline Total emphysema score & $5(1-15)$ & $9.5(2-18)$ & $0.191^{\#}$ \\
\hline Total upper zone emphysema & $3.5(0-6)$ & $5.5(1-7)$ & $0.214^{\#}$ \\
\hline Total lower zone emphysema & $0(0-3)$ & $0.5(0-4)$ & $0.178^{\#}$ \\
\hline Total fibrosis score & $0(0-2)$ & $0(0-2.5)$ & $0.509^{\#}$ \\
\hline Total upper zone fibrosis & $0(0-0)$ & $0(0-0)$ & $0.790^{\#}$ \\
\hline Total lower zone fibrosis & $0(0-1.5)$ & $0(0-2)$ & $0.330^{\#}$ \\
\hline Pulmonary artery/aorta & $1.0 \pm 0.1$ & $1.0 \pm 0.1$ & 0.202 \\
\hline Right ventricle/left ventricle & $1.1 \pm 0.4$ & $1.3 \pm 0.4$ & 0.031 \\
\hline
\end{tabular}

Data are presented as \%, mean + SD or median (interquartile range), unless otherwise stated. COPD: chronic obstructive pulmonary disease; PAP: pulmonary arterial pressure; BMI: body mass index; WHO-FC: World Health Organization functional class; ISWD: incremental shuttle walking distance; $\mathrm{SpO}_{2}$ : arterial oxygen saturation measured by pulse oximetry; $\mathrm{PaCO}_{2}$ : arterial carbon dioxide tension; $\mathrm{PaO}_{2}$ : arterial oxygen tension; RAP: right atrial pressure; $\mathrm{Cl}$ : cardiac index by thermodilution method; PCWP: pulmonary capillary wedge pressure; PVR: pulmonary vascular resistance; $\mathrm{SvO}_{2}$ : mixed venous oxygen saturation; FEV1: forced expiratory volume in $1 \mathrm{~s}$; \% pred: \% predicted; FVC: forced vital capacity; DLCO: diffusing capacity of the lung for carbon monoxide; CT: computed tomography. Total emphysema score: sum total of emphysema scores for all six lung zones; total fibrosis score: sum total of fibrosis scores for all six lung zones; upper zone emphysema score: sum total of emphysema for upper zones bilaterally; lower zone emphysema score: sum total of emphysema for

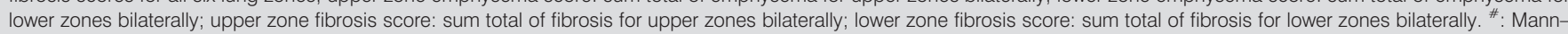
Whitney U-test used for non-parametric data.

data. The Wilcoxon matched-pairs test was used to compare upper zone with lower zone emphysema and fibrosis scores on HRCT. Categorical data were compared using with the Chisquared test. Survival from date of diagnosis was estimated using the Kaplan-Meier method, with comparison between groups performed by the log-rank test. Predictors of survival were assessed using forward stepwise Cox regression analysis. Variables with a $\mathrm{p}$-value $<0.05$ at univariate analysis were 
considered for multivariate analysis. Due to colinearity only two pulmonary haemodynamic parameters (mean PAP and mixed venous oxygen saturation $\left.\left(\mathrm{SvO}_{2}\right)\right)$ were used in the multivariate model, and in view of less complete data, HRCT emphysema scores were not entered into the multivariate model. Receiver operating characteristics (ROC) curve analysis of survival at 2 years was used to derive threshold values for predictors of survival. The relationship between continuous variables was calculated using Pearson's correlation test. A p-value of $<0.05$ was deemed statistically significant throughout. Statistical analysis was performed using PASW Statistics v18 (SPSS, Chicago, IL, USA).

\section{RESULTS}

\section{Demographics and baseline characteristics}

The study cohort comprised 101 patients with PH-COPD. Mean age at diagnosis was $68.5 \pm 9.7$ years with a male preponderance of $63 \% ; 99 \%$ were Caucasian. The maximal duration of follow-up was 9 years with a mean follow-up of $2.3 \pm 1.9$ years. During follow-up, 62 (61\%) patients died and no patients underwent lung transplantation. Patients were assessed in clinical stability outside infective exacerbations; median C-reactive protein was $6.7 \mathrm{mg} \cdot \mathrm{L}^{-1}\left(3.9-11.5 \mathrm{mg} \cdot \mathrm{L}^{-1}\right)$ and median neutrophil count was $6.0 \times 10^{9} \cdot \mathrm{L}^{-1}(4.8-$ $\left.7.6 \times 10^{9} \cdot \mathrm{L}^{-1}\right)$. In 74 patients in whom HRCT scans were available for scoring, interobserver agreement was $\kappa=0.74$ $(\mathrm{p}<0.001)$. Maximum discrepancy between radiologists per zone was 1 point. This occurred in $13 \%$ of the zones scored and mean score was used for further analysis. In patients in whom scans could not be retrieved to allow formal scoring no significant fibrosis was noted on clinical reports.

In 42 patients, $\mathrm{PH}$ was mild to moderate (mean PAP 25$39 \mathrm{mmHg}$ ) and in 59 patients $\mathrm{PH}$ was severe (mean PAP $\geqslant 40 \mathrm{mmHg}$ ). In those with severe $\mathrm{PH}$ there was haemodynamic evidence of impaired cardiac function with elevated right atrial pressure, reduced cardiac index and mixed venous oxygen saturations (table 1). The phenotype of severe PH-COPD was also characterised by greater impairment of gas exchange, despite better preserved spirometry, but no statistically significant difference in the severity of emphysema on HRCT scan. Oxygen saturations at rest on room air were significantly lower in those with severe PH-COPD $(\mathrm{p}<0.001)$, but this hypoxaemia was adequately corrected, albeit requiring higher flows of longterm oxygen to achieve this. Eight patients with severe $\mathrm{PH}$ COPD had pulmonary capillary wedge pressure (PCWP) $>15 \mathrm{mmHg}$, but there was no difference in the prevalence of cardiac comorbidities when comparing the group with elevated PCWP to those with PCWP $\leqslant 15 \mathrm{mmHg}$. In addition, the mean left atrial size (maximum anterior-posterior diameter) on $\mathrm{CT}$ scan in patients with PCWP $\leqslant 15 \mathrm{mmHg}$ at $3.6 \pm 0.9 \mathrm{~cm}$ was not significantly different to the $3.5 \pm 0.8 \mathrm{~cm}$ seen in patients with elevated wedge pressure $(\mathrm{p}=0.749)$.

Overall on HRCT scan, 43 patients had no evidence of pulmonary fibrosis. Emphysematous change was more marked in the upper zones compared to the lower zones, whereas if a degree of fibrosis was noted this was more prominent in the lower zones (Wilcoxon matched pairs test, $\mathrm{p}$ both <0.001). Difference in overall HRCT scores for emphysema or fibrosis between those with mild-moderate versus severe PH-COPD did not reach statistical significance (table 1).
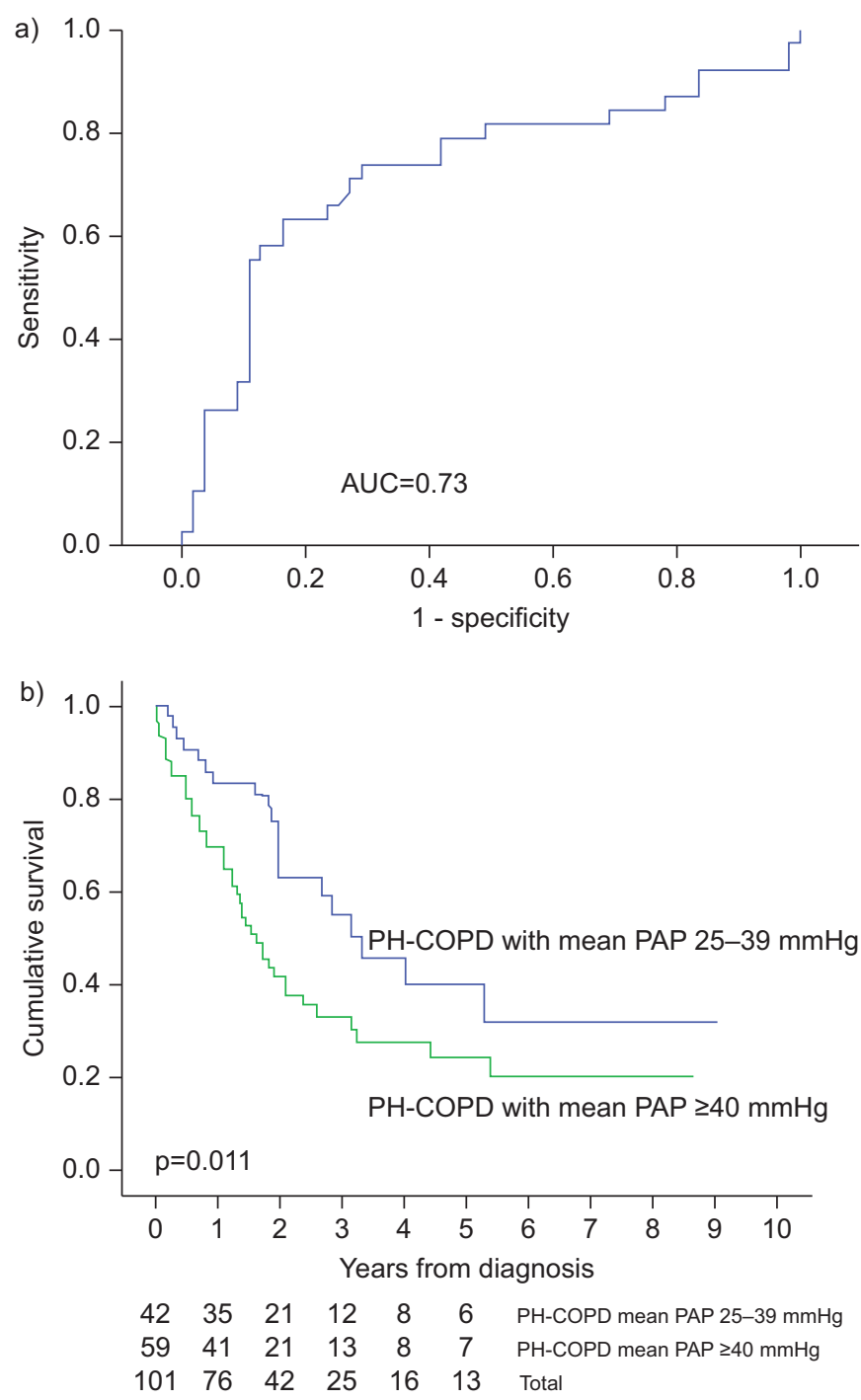

FIGURE 2. a) Receiver operating characteristics curve analysis of survival at 2 years for mean pulmonary arterial pressure (PAP) in pulmonary hypertension associated with chronic obstructive pulmonary disease (COPD); b) cumulative survival from date of diagnosis in pulmonary hypertension associated with COPD by mean PAP. AUC: area under the curve.

\section{Noninvasive assessments}

Estimated systolic PAP measured using echocardiogram correlated weakly with systolic PAP directly measured at RHC $(\mathrm{r}=0.54, \mathrm{p}<0.01)$. In $61 \%$ of patients the estimated sysytolic PAP on echocardiogram differed from measured systolic PAP at RHC by $>10 \mathrm{mmHg}$. There were weak correlations between mean PAP and the pulmonary artery and aortic diameter ratio, right ventricular and left ventricular diameter ratio measured on CT-scan and diffusing capacity of the lung for carbon monoxide (DLCO) $(r=0.17,0.29$ and 0.39, respectively, $\mathrm{p}<0.05)$.

\section{Survival and prognostic indicators}

In those with severe PH-COPD, 1-year survival was 70\% and 3year survival was $33 \%$, which is significantly worse than the $83 \%$ and 55\%, respectively, seen in mild-moderate PH-COPD (fig. 2b) $(\mathrm{p}=0.011)$. ROC curve analysis confirmed mean PAP 
of $40 \mathrm{mmHg}$ to be the optimal mean PAP threshold (sensitivity $68 \%$, false-positive rate $45 \%$ ) for determining survival (fig. 2a). At multivariate analysis, age, DLCO, $\mathrm{SvO}_{2}$ and $\mathrm{WHO}$ functional class (table 2) were independent predictors of survival. For these patients with $\mathrm{PH}-\mathrm{COPD}$, ROC curve analysis for age showed 73 years (sensitivity 58\%, false-positive $26 \%$ ); for DLCO $27 \%$ (sensitivity 69\%, false-positive 32\%); and for $\mathrm{SvO}_{2} 65 \%$ (sensitivity $80 \%$, false-positive $46 \%$ ) to be the optimal thresholds for predicting survival (fig. 3a-c) $(p \leqslant 0.001)$. 3-year survival in patients with PH-COPD in WHO functional class III at diagnosis was $47 \%$, superior to $20 \%$ for patients presenting in WHO functional class IV (fig. 3d) $(p=0.001)$.

\section{Treatment in PH-COPD}

43 patients with severe PH-COPD were treated compassionately with pulmonary vascular therapies; first-line treatment was with PDE-5I in 31 patients, ERA in 10 patients, s.c. treprostinil in one patient and nebulised iloprost in one patient (table 3). All patients received targeted pulmonary vascular therapy for at $\geqslant 3$ months, unless death occurred before this time. In the group of patients with severe PH-COPD survival for the 43 treated patients was similar to the 16 untreated patients (fig. 4a), despite pulmonary haemodynamics being significantly worse in these patients who received therapy (table 4). For the purposes of this study, clinical improvement was defined as a reduction of $>20 \%$ in pulmonary vascular resistance (PVR) or improvement in WHO functional class. At follow-up, RHC data was available for seven patients and showed $>20 \%$ reduction in PVR in four patients. A further four patients experienced an improvement in WHO functional class after $4 \pm 2$ months of treatment. The eight patients who demonstrated clinical improvement had superior survival when compared to the 35 patients receiving pulmonary vascular treatment without objective improvement (fig. 4b), even though there was no significant difference in demographics, haemodynamic severity, PFTs or HRCT scan scores between the two groups.

The effect of targeted pulmonary vascular therapy on oxygenation was assessed. For patients receiving PDE-5I, oxygen saturations at baseline and following the initial dose of PDE-5I were available for 21 patients. Median maximal desaturation within $4 \mathrm{~h}$ of acute dosing for this group was $-1 \%$ $(-0.5--2 \%)$, with two patients desaturating $\geqslant 4 \%$ and one patient improving their oxygen saturations by $\geqslant 4 \%$. Longterm follow-up data was analysed for patients receiving all forms of targeted pulmonary vascular therapy where oxygen saturations on air were available at baseline and follow-up. After a median 178 days of therapy, oxygen saturation on air increased by $1 \%(-2-7 \%)$ in 28 patients. There were no patients in whom there was a clinically significantly reduction in oxygen saturation with PDE-5I that resulted in discontinuation

\begin{tabular}{|c|c|c|c|c|}
\hline & Univariate hazard ratio $(95 \% \mathrm{Cl})$ & p-value & Multivariate hazard ratio $(95 \% \mathrm{Cl})$ & p-value \\
\hline Age years & $1.054(1.024-1.086)$ & $<0.001$ & $1.040(1.004-1.078)$ & 0.031 \\
\hline \multicolumn{5}{|l|}{ Sex } \\
\hline Female & Reference & & & \\
\hline \multicolumn{5}{|l|}{ WHO-FC } \\
\hline III & Reference & & Reference & \\
\hline IV & $2.471(1.421-4.296)$ & 0.002 & $0.485(0.249-0.943)$ & 0.033 \\
\hline ISWD m & $0.996(0.993-0.999)$ & 0.011 & & \\
\hline \multicolumn{5}{|l|}{ Haemodynamics } \\
\hline PVR dyn $\cdot \mathrm{S} \cdot \mathrm{cm}^{-5}$ & $1.001(1.001-1.002)$ & $<0.001$ & & \\
\hline $\mathrm{SvO}_{2} \%$ & $0.918(0.887-0.950)$ & $<0.001$ & $0.947(0.910-0.986)$ & 0.008 \\
\hline \multicolumn{5}{|l|}{ HRCT scores } \\
\hline Total emphysema & $1.047(1.008-1.088)$ & 0.018 & & \\
\hline Total fibrosis & $1.034(0.956-1.119)$ & 0.407 & & \\
\hline \multicolumn{5}{|l|}{ Pulmonary function } \\
\hline FEV $1 \%$ pred & $1.011(1.001-1.025)$ & 0.006 & & \\
\hline FVC \% pred & $1.011(1.001-1.022)$ & 0.039 & & \\
\hline DLco \% pred & $0.964(0.946-0.982)$ & $<0.001$ & $0.975(0.954-0.996)$ & 0.020 \\
\hline
\end{tabular}

BMI: body mass index; WHO-FC: World Health Organization functional class; ISWD: incremental shuttle walking distance; RAP: right atrial pressure; PAP: pulmonary arterial pressure; $\mathrm{Cl}$ : cardiac index; PCWP: pulmonary capillary wedge pressure; PVR: pulmonary vascular resistance; $\mathrm{SvO}_{2}$ : mixed venous oxygen saturation; HRCT: high-resolution computed tomography; FEV1: forced expiratory volume in $1 \mathrm{~s}$; \% pred: \% predicted; FVC: forced vital capacity; DLCo: diffusing capacity of the lung for carbon monoxide 

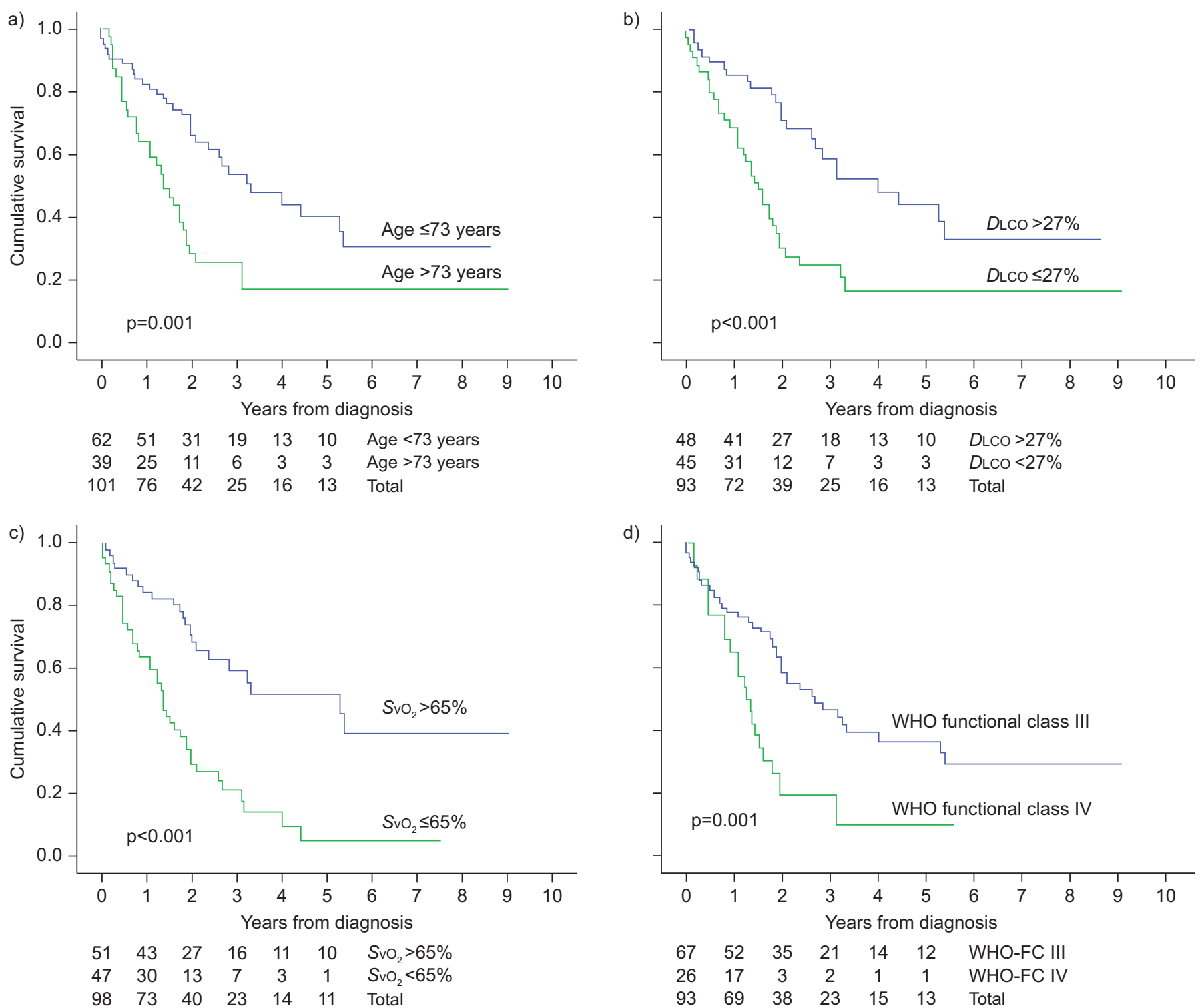

FIGURE 3. Cumulative survival from date of diagnosis in pulmonary hypertension associated with chronic obstructive pulmonary disease by receiver operating characteristic curve-derived thresholds of a) age; b) diffusing capacity of the lung for carbon monoxide (DLCO) and c) mixed venous oxygen saturation ( $\left.\mathrm{SvO}_{2}\right)$; and by d) World Health Organization functional class (WHO-FC) at diagnosis.

of therapy. In follow-up, exercise testing for patients receiving targeted pulmonary vascular therapy was variably performed and incomplete and did not allow for meaningful analysis.

\section{DISCUSSION}

This study describes several important observations regarding the largest cohort of patients with severe PH-COPD yet studied. First, we have confirmed a phenotype of markedly reduced gas transfer and greater hypoxaemia despite less pronounced airflow obstruction when compared to those with mild-moderate PH-COPD [4, 5]. In addition, we have demonstrated significantly worse WHO functional class and exercise capacity in severe PH-COPD, with a poor prognosis and a disease trajectory that is significantly worse than patients with mild-moderate PH-COPD [5, 29].
While $\mathrm{SvO}_{2}$ has prognostic value in unselected patients with COPD [30], independent prognostic markers in patients with $\mathrm{PH}$ in COPD have not previously been described. We have identified age, DLCO, $\mathrm{SvO}_{2}$ and WHO functional class as independent predictors of survival in PH-COPD. Although a mean PAP $\geqslant 40 \mathrm{mmHg}$ is traditionally used to define those with severe $\mathrm{PH}-\mathrm{COPD}, \mathrm{SvO}_{2} \leqslant 65 \%$ and $\mathrm{DL}, \mathrm{CO} \leqslant 27 \%$ are perhaps better thresholds to define poor outcome in $\mathrm{PH}-$ COPD. It is interesting to note, however, that a mean PAP of $40 \mathrm{mmHg}$, the traditionally used threshold for describing severe PH-COPD, was in fact the optimal mean PAP value derived by ROC curve analysis of subsequent survival. These important parameters have utility in counselling patients regarding prognosis. In addition, while in mild-moderate PH-COPD exercise capacity is limited by exhaustion of ventilatory reserve [31], mean $\mathrm{PAP} \geqslant 40 \mathrm{mmHg}$ has recently 
TABLE 3 Therapy of patients with pulmonary hypertension $(\mathrm{PH})$ associated with chronic obstructive pulmonary disease (COPD)

COPD mean PAP $25-39 \mathrm{mmHg}$

COPD mean PAP $\geqslant 40 \mathrm{mmHg}$

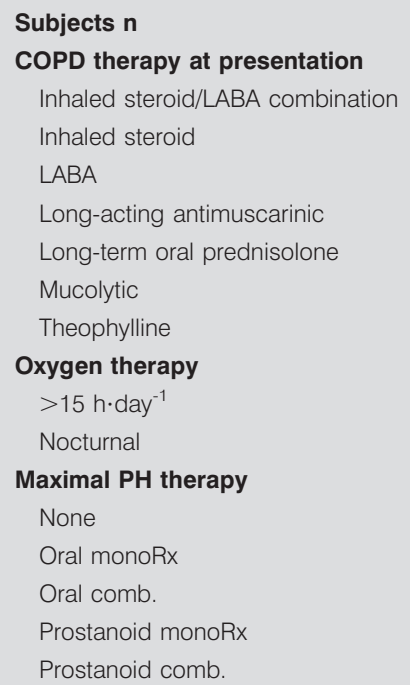

59

51

14

10

51

14

12

15

85

3

27.1

64.4

5.1

1.7

1,7

Data are presented as \%, unless otherwise stated. Prostanoid therapy was with nebulised or i.v. iloprost or s.c. treprostinil. PAP: pulmonary artery pressure; LABA: Iongacting $\beta$-agonist; oral monoRx: oral monotherapy; oral comb.: combination of phosphodiesterare-5-inhibitor and endothelin receptor antagonist; prostanoid monoRx: prostanoid monotherapy; prostanoid comb.: prostanoid in combination with any other targeted therapy(ies).

been shown to characterise patients with PH-COPD who have an exhausted circulatory reserve on exercise [32].

Patients with severe PH-COPD were more hypoxaemic on room air and more hypocarbic; the latter presumably reflecting hyperventilation to improve oxygenation. Interestingly, although hypoxaemia was adequately corrected by long term oxygen therapy, severe $\mathrm{PH}$ persisted. These observations support the hypothesis that hypoxia is not the sole driver of severe PH-COPD $[2,33]$. There is little data supporting the use of pulmonary vasodilators used in $\mathrm{PAH}$ in patients with $\mathrm{PH}-\mathrm{COPD}$ [34-37]. However, there is growing interest in considering randomised controlled trials (RCTs) in this population, given the pulmonary haemodynamic characteristics of these patients. In the present study, patients with severe PH-COPD who received compassionate treatment with targeted pulmonary vasodilator therapy had a very poor outcome with a 1-year survival of $72 \%$, which was not significantly different to those who did not receive targeted therapy $(63 \%, p=0.672)$, although the treated group had more severe pulmonary haemodynamics. The lack of a demonstrated survival benefit, however, does not necessarily confirm a lack of efficacy, but does suggest that with current targeted therapies the outcome for the group as a whole remains poor. Mechanisms suggested to contribute to the severe haemodynamic change seen in patients with severe PH-COPD include destruction of the capillary vascular bed or the development of a vasculopathy [4,5]. Interestingly, the $19 \%$ of patients with severe $\mathrm{PH}-\mathrm{COPD}$ identified arbitrarily as having an objective response to therapy based on improvements in WHO functional class or a $>20 \%$ fall in PVR had a superior survival compared to nonresponders and may represent a phenotype in which there is a greater degree of potentially treatment-responsive vasculopathy compared to emphysematous obliteration of the pulmonary microvascular bed. Although these observations are based on small numbers they do raise the possibility that a proportion of patients with $\mathrm{PH}-\mathrm{COPD}$ may derive benefit from targeted therapies and support further investigation in the context of RCTs. A previous study raised concerns regarding acute worsening of oxygen saturation in patients with modest PH-COPD but more severe airflow obstruction who receive a dose of sildenafil [34]. In the current study no clinically significant worsening of oxygen saturations was observed acutely in patients receiving sildenafil, although these results should be treated with caution as this study was not primarily designed to assess this effect. Importantly, we have identified markers of disease severity in PH-COPD that may be helpful in defining patient groups for further study, and given the extremely high observed mortality, survival may be an appropriate end-point in such studies. Whether exercise testing is an appropriate end-point for studies in PH-COPD cannot be ascertained by this study.

We have recently also shown the importance of accurate phenotyping of patients with $\mathrm{PH}$ using multi-modality assessment, including imaging and RHC, and that classification predicts outcome [17]. A significant number of patients with severe PH-COPD had spirometric values which would have allowed entry into RCTs of therapies for IPAH and would have met registry criteria for IPAH [38], despite their having severe emphysema. This observation emphasises the importance of HRCT assessment of lung parenchyma in those with RHC parameters suggestive of IPAH. In the ASPIRE registry patients who clearly had combined fibrosis-emphysema syndrome were classified as having PH-lung secondary to 

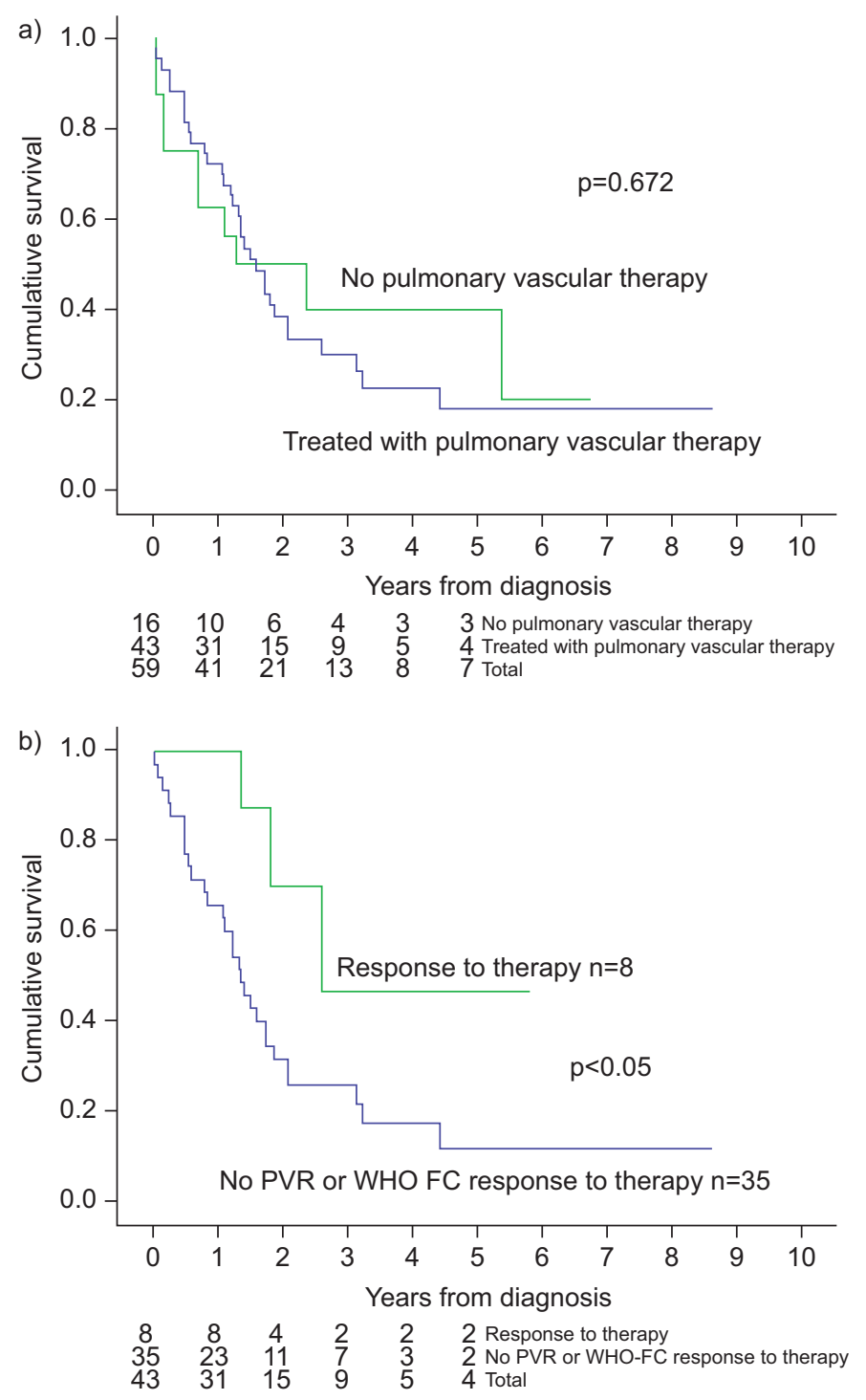

FIGURE 4. a) Cumulative survival from date of diagnosis in patients with pulmonary hypertension associated with chronic obstructive pulmonary disease (COPD) and mean pulmonary artery pressure (PAP) $\geqslant 40 \mathrm{mmHg}$ by use of pulmonary vascular treatment; b) cumulative survival from diagnosis in patients with pulmonary hypertension associated with COPD and mean PAP $\geqslant 40 \mathrm{mmHg}$ by features of response to pulmonary vascular treatment (improvement in World Health Organization functional class (WHO FC) or fall in pulmonary vascular resistance (PVR) $>20 \%$ ) compared to those without response.

mixed obstructive and restrictive defects, and were not enrolled in the current study. On further detailed quantitative radiological evaluation for the purposes of this study (not available at the time of initial classification), two patients with a diagnosis of PH-COPD did have more significant elevation of fibrosis scores. However, emphysema scores for both of these patients were greater than their fibrosis scores. The vast majority of patients otherwise had no or minimal fibrosis and when present its extent was not significantly different between the mild-moderate PH-COPD and severe PH-COPD groups.

In this study patients were catheterised in clinical stability without exacerbations, which are associated with significant rises in mean PAP [39]. Noninvasive measures in these patients did not correlate reliably with mean PAP at RHC, as described elsewhere [40]. This compounds the difficulty in distinguishing patients with severe PH-COPD from patients with severe COPD without $\mathrm{PH}$ and emphasises the importance of cardiac catheterisation where knowledge of the patient's pulmonary vascular status is important. The presence of features of the phenotype of severe $\mathrm{PH}$ described here and elsewhere [4], such as a very low DLCO or severe hypoxaemia in the setting of relatively well preserved spirometry can raise suspicion, although thorough investigation is required to characterise these patients and to exclude other causes of $\mathrm{PH}$ and is best performed at specialist centres, through which RCTs of therapies may be coordinated [33].

COPD is a systemic disease and the BODE (body mass index (BMI), airflow obstruction, dyspnoea, exercise capacity) index recognises $\mathrm{BMI}$ in addition to markers of reduced respiratory reserve, namely FEV1, Medical Research Council dyspnoea score and exercise capacity as important prognostic markers [41]. In the current study, functional class, as well as age at diagnosis and measures of gas transfer and cardiac function, was shown to independently predict survival, but importantly FEV1, BMI and exercise capacity did not. This implies that conventional COPD prognostic models may not apply in patients with PH-COPD. This is noteworthy in view of the increasing interest in the accurate phenotyping of distinct subgroups of patients with COPD.

This study has certain limitations. The population studied represents a highly selected cohort of patients referred to a supra-regional $\mathrm{PH}$ referral centre in whom the elevation in PAP was thought to be out of proportion to the severity of underlying respiratory disease. Therefore no estimate of the incidence or prevalence of PH-COPD in the COPD population can be drawn from this study. Also, despite the routine use of HRCT scan in diagnostic evaluation, HRCT films were unavailable for scoring for 27 patients. However, pulmonary function did not significantly differ in the group with and the group without CT films available for scoring (data not shown). Furthermore, the clinical reports of HRCT were consulted as part of data collection to confirm that patients did not have significant pulmonary fibrosis. A small number of patients in whom COPD was the clear cause for $\mathrm{PH}$, but who had elevations in PCWP without increased prevalence of cardiovascular morbidity, were included in the cohort. In these patients, left heart disease was not thought to be the cause of pulmonary hypertension and, indeed, the left atrium size was usually normal in these patients.

\section{Conclusion}

Patients referred to a specialist centre with $\mathrm{PH}-\mathrm{COPD}$ have a poor prognosis that can be best predicted by age, functional status and markers of gas exchange and transport, but not by FEV1. Despite this poor prognosis, our data suggests that a subgroup of patients may exhibit a clinical response to pulmonary vascular therapies used in PAH. Given the high mortality of this condition, studies of specific treatment for PH-COPD are needed.

\section{SUPPORT STATEMENT}

This work was supported by an unrestricted educational grant from Actelion pharmaceuticals (J. Hurdman); Medical Research Council 
TABLE 4 Characteristics of patients with pulmonary hypertension associated with chronic obstructive pulmonary disease (COPD) and mean pulmonary artery pressure (PAP) $\geqslant 40 \mathrm{mmHg}$ by treatment group

\begin{tabular}{|c|c|c|c|}
\hline Age years & $70 \pm 10$ & $70 \pm 6$ & 0.826 \\
\hline Female \% & 30 & 31 & 0.940 \\
\hline \multicolumn{4}{|l|}{ Exercise limitation } \\
\hline \multicolumn{4}{|l|}{ Right heart catheter } \\
\hline Entrained $\mathrm{O}_{2} \mathrm{~L} \cdot \mathrm{min}^{-1}$ & $3.0(0-5.5)$ & $2.0(0-5.3)$ & $0.439^{\#}$ \\
\hline Resting $\mathrm{SpO}_{2} \%$ & $95 \pm 4$ & $93 \pm 3$ & 0.126 \\
\hline Mean RAP mmHg & $12 \pm 5$ & $13 \pm 7$ & 0.573 \\
\hline Mean PAP $\mathrm{mmHg}$ & $51 \pm 7$ & $45 \pm 8$ & 0.015 \\
\hline $\mathrm{Cl} \mathrm{L} \cdot \mathrm{min} \cdot \mathrm{m}^{-2}$ & $2.3 \pm 0.7$ & $2.9 \pm 0.8$ & 0.016 \\
\hline \multicolumn{4}{|l|}{ Pulmonary function tests } \\
\hline FEV $1 \%$ pred & $71 \pm 23$ & $50 \pm 18$ & 0.003 \\
\hline FVC \% pred & $95 \pm 23$ & $76 \pm 24$ & 0.010 \\
\hline DLCO \% pred & $26 \pm 13$ & $29 \pm 12$ & 0.532 \\
\hline \multicolumn{4}{|l|}{ CT scan } \\
\hline Total emphysema score & $9(2-18.3)$ & $10.5(1.9-15.7)$ & $0.876^{\#}$ \\
\hline Total fibrosis score & $0.5(0-3.3)$ & $0(0-1.5)$ & $0.199^{\#}$ \\
\hline
\end{tabular}

Data are presented as mean \pm SD or median (interquartile range), unless otherwise stated. Total emphysema score represents the sum total of emphysema scores for all six lung zones; total fibrosis score represents sum total of fibrosis scores for all six lung zones. WHO-FC: World Health Organization functional class; ISWD: incremental shuttle walking distance; $\mathrm{SpO}_{2}$ : arterial oxygen saturation measured by pulse oximetry; RAP: right atrial pressure; $\mathrm{Cl}$ : cardiac index measured by thermodilution method; PCWP: pulmonary capillary wedge pressure; PVR: pulmonary vascular resistance; $\mathrm{SvO}_{2}$ : mixed venous oxygen saturation; FEV1: forced expiratory volume in $1 \mathrm{~s}$; \% pred: \% predicted; FVC: forced vital capacity; DLCO: diffusing capacity of the lung for carbon monoxide; CT: computed tomography. ${ }^{\#}$ : Mann-Whitney U-test used for nonparametric data.

Career Development Award [grant number G0800318] (A. Lawrie); the National Institute for Health Research Sheffield Cardiovascular Biomedical Research Unit (R. Condliffe, C.A. Elliot, A. Swift, J.M. Wild, I. Sabroe, D.G. Kiely).

\section{STATEMENT OF INTEREST}

Conflict of interest information can be found alongside the online version of this article at www.erj.ersjournals.com

\section{REFERENCES}

1 Weitzenblum E, Hirth C, Ducolone A, et al. Prognostic value of pulmonary artery pressure in chronic obstructive pulmonary disease. Thorax 1981; 36: 752-758.

2 Sims MW, Margolis DJ, Localio AR, et al. Impact of pulmonary artery pressure on exercise function in severe COPD. Chest 2009; 136: 412-419.

3 Kessler R, Faller M, Weitzenblum E, et al. "Natural history" of pulmonary hypertension in a series of 131 patients with chronic obstructive lung disease. Am J Respir Crit Care Med 2001; 164: 219-224.

4 Chaouat A, Bugnet AS, Kadaoui N, et al. Severe pulmonary hypertension and chronic obstructive pulmonary disease. Am J Respir Crit Care Med 2005; 172: 189-194.
5 Thabut G, Dauriat G, Stern JB, et al. Pulmonary hemodynamics in advanced COPD candidates for lung volume reduction surgery or lung transplantation. Chest 2005; 127: 1531-1536.

6 Weitzenblum E, Schrijen F, Mohan-Kumar T, et al. Variability of the pulmonary vascular response to acute hypoxia in chronic bronchitis. Chest 1988; 94: 772-778.

7 Yildiz P, Oflaz H, Cine N, et al. Gene polymorphisms of endothelial nitric oxide synthase enzyme associated with pulmonary hypertension in patients with COPD. Respir Med 2003; 97: 1282-1288.

8 Wiebe BM, Laursen H. Lung morphometry by unbiased methods in emphysema: bronchial and blood vessel volume, alveolar surface area and capillary length. APMIS 1998; 106: 651-656.

9 Saetta M, Baraldo S, Corbino L, et al. CD8+ve cells in the lungs of smokers with chronic obstructive pulmonary disease. Am J Respir Crit Care Med 1999; 160: 711-717.

10 Peinado VI, Barberá JA, Abate $\mathrm{P}$, et al. Inflammatory reaction in pulmonary muscular arteries of patients with mild chronic obstructive pulmonary disease. Am J Respir Crit Care Med 1999; 159: 1605-1611.

11 Wright JL, Petty T, Thurlbeck WM. Analysis of the structure of the muscular pulmonary arteries in patients with pulmonary hypertension and COPD: National Institutes of Health nocturnal oxygen therapy trial. Lung 1992; 170: 109-124.

12 Celli BR, MacNee W. Standards for the diagnosis and treatment of patients with COPD: a summary of the ATS/ERS position paper. Eur Respir J 2004; 23: 932-946. 
13 Boutin-Forzano S, Moreau D, Kalaboka S, et al. Reported prevalence and co-morbidity of asthma, chronic bronchitis and emphysema: a pan-European estimation. Int J Tuberc Lung Dis 2007; 11: 695-702.

14 Bousquet J, Dahl R, Khaltaev N. Global Alliance against Chronic Respiratory Diseases. Eur Respir J 2007; 29: 233-239.

15 Humbert M, Simonneau G. Vasodilators in patients with chronic obstructive pulmonary disease and pulmonary hypertension: not ready for prime time! Am J Respir Crit Care Med 2010; 181: 202-203.

16 Smith CJ, Gribbin J, Challen KB, et al. The impact of the 2004 NICE guideline and 2003 General Medical Services contract on COPD in primary care in the UK. QJM 2008; 101: 145-153.

17 Hurdman J, Condliffe R, Elliot CA, et al. ASPIRE registry: assessing the Spectrum of Pulmonary hypertension Identified at a REferral centre. Eur Respir J 2012; 39: 945-955.

18 Simonneau G, Robbins IM, Beghetti M, et al. Updated clinical classification of pulmonary hypertension. J Am Coll Cardiol 2009; 54: Suppl. 1, S43-S54.

19 National Institute for Health and Clinical Excellence. Chronic Obstructive Pulmonary Disease. Management of chronic obstructive pulmonary disease in adults in primary and secondary care (partial update). http:/ /guidance.nice.org.uk/CG101/NICEGuidance/pdf/ English Date last accessed: April 26, 2012. Date last updated: June 2010.

20 Kazerooni EA, Martinez FJ, Flint A, et al. Thin-section CT obtained at 10-mm increments versus limited three-level thin-section CT for idiopathic pulmonary fibrosis: correlation with pathologic scoring. AJR Am J Roentgenol 1997; 169: 977-983.

21 Kitaguchi Y, Fujimoto K, Hanaoka M, et al. Clinical characteristics of combined pulmonary fibrosis and emphysema. Respirology 2010; 15: 265-271.

22 Cotes JE, Chinn DJ, Quanjer PH, et al. Standardization of the measurement of transfer factor (diffusing capacity). Report Working Party "Standardization of Lung Function Tests", European Community for Steel and Coal. Official Statement of the European Respiratory Society. Eur Respir J 1993; 6: Suppl. 16, 41-52.

23 Quanjer PH, Tammeling GJ, Cotes JE, et al. Lung volumes and forced ventilatory flows. Report Working Party Standardization of Lung Function Tests, European Community for Steel and Coal. Official Statement of the European Respiratory Society. Eur Respir J 1993; 6: Suppl. 16, 5-40.

24 Singh SJ, Morgan MD, Scott S, et al. Development of a shuttle walking test of disability in patients with chronic airways obstruction. Thorax 1992; 47: 1019-1024.

25 BTS guidelines for the management of chronic obstructive pulmonary disease. The COPD Guidelines Group of the Standards of Care Committee of the BTS. Thorax 1997; 52: Suppl. 5, S1-S28.

26 National Institute for Clinical Excellence. Chronic obstructive pulmonary disease. Management of chronic obstructive pulmonary disease in adults in primary and secondary care clinical guideline 12. Feb 2004. www.nice.org.Uk/guidance/CG12

27 Haest I, Kiely DG, Needham L, et al. NORCOM Policy on Pulmonary Hypertension. Sheffield Public Health Network, 2004. www.doncasterpct.nhs.uk/documents/Appendix2.pdf Date last accessed: April 26, 2012.

28 NHS National Specialised Commissioning Group. Commissioning Policy - Target Therapies for the Treatment of Pulmonary Arterial Hypertension in Adults. www.emscg.nhs.uk/library/P009V1 NationalSpecialisedCommissioningGroupPolicy2.pdf Date last accessed: April 26, 2012. Date last updated: January 14, 2009.

29 Weitzenblum E, Sautegeau A, Ehrhart M, et al. Long-term course of pulmonary arterial pressure in chronic obstructive pulmonary disease. Am Rev Respir Dis 1984; 130: 993-998.

30 Kawakami Y, Kishi F, Yamamoto H, et al. Relation of oxygen delivery, mixed venous oxygenation, and pulmonary hemodynamics to prognosis in chronic obstructive pulmonary disease. N Engl J Med 1983; 308: 1045-1049.

31 Pynnaert C, Lamotte M, Naeije R. Aerobic exercise capacity in COPD patients with and without pulmonary hypertension. Respir Med 2010; 104: 121-126.

32 Boerrigter BG, Bogaard HJ, Trip $\mathrm{P}$, et al. Ventilatory and cardiocirculatory exercise profiles in COPD: the role of pulmonary hypertension. Chest 2012; 142: 1166-1174.

33 Chaouat A, Naeije R, Weitzenblum E. Pulmonary hypertension in COPD. Eur Respir J 2008; 32: 1371-1385.

34 Blanco I, Gimeno E, Munoz PA, et al. Hemodynamic and gas exchange effects of sildenafil in patients with chronic obstructive pulmonary disease and pulmonary hypertension. Am J Respir Crit Care Med 2010; 181: 270-278.

35 Archer SL, Mike D, Crow J, et al. A placebo-controlled trial of prostacyclin in acute respiratory failure in COPD. Chest 1996; 109: 750-755.

36 Stolz D, Rasch H, Linka A, et al. A randomised, controlled trial of bosentan in severe COPD. Eur Respir J 2008; 32: 619-628.

37 Dernaika TA, Beavin M, Kinasewitz GT. Iloprost improves gas exchange and exercise tolerance in patients with pulmonary hypertension and chronic obstructive pulmonary disease. Respiration 2010; 79: 377-382.

38 Humbert M, Sitbon O, Chaouat A, et al. Pulmonary arterial hypertension in France: results from a national registry. Am J Respir Crit Care Med 2006; 173: 1023-1030.

39 Abraham AS, Cole RB, Green ID, et al. Factors contributing to the reversible pulmonary hypertension of patients with acute respiratory failure studies by serial observations during recovery. Circ Res 1969; 24: 51-60.

40 Arcasoy SM, Christie JD, Ferrari VA, et al. Echocardiographic assessment of pulmonary hypertension in patients with advanced lung disease. Am J Respir Crit Care Med 2003; 167: 735-740.

41 Celli BR, Cote CG, Marin JM, et al. The body-mass index, airflow obstruction, dyspnea, and exercise capacity index in chronic obstructive pulmonary disease. N Engl J Med 2004; 350: 1005-1012. 